\title{
Slow release carbohydrate and the treatment of diabetes
}

By David J. A. Jenkins, Department of Nutrition and Food Science, Faculty of Medicine, University of Toronto, Toronto, Ontario, Canada $M_{5} S$ I $A 8$ and Thomas M. S. Wolever, University Laboratory of Physiology, Oxford

\section{Introduction-lente carbohydrate}

The concept of slow release or 'lente' carbohydrate owes much to the original dietary fibre hypothesis of the early r 970 (Trowell \& Burkitt, 1975). In this it was suggested that many western ills are due to changes in the diet involving the refining of carbohydrate foods and the elimination of dietary fibre from the diet (i.e. the loss of the unabsorbable or 'unavailable' carbohydrate and lignin). Amongst this list was included diabetes (Trowell, 1975).

A rationale then evolved that unabsorbable materials may interfere with the uptake of nutrients perhaps by increasing the thickness of the unstirred layer, perhaps even causing malabsorption. In man's original diet (Fig. I) foods with low energy concentrations were seen as releasing their carbohydrate products of digestion slowly and utilizing a greater length of small intestine for absorption. By contrast, refined western foods were rapidly absorbed high in the small intestine. The more primitive diet (Fig. 2) would then result in prolongation and flattening of the postprandial blood glucose response while the refined diet produced a large rise

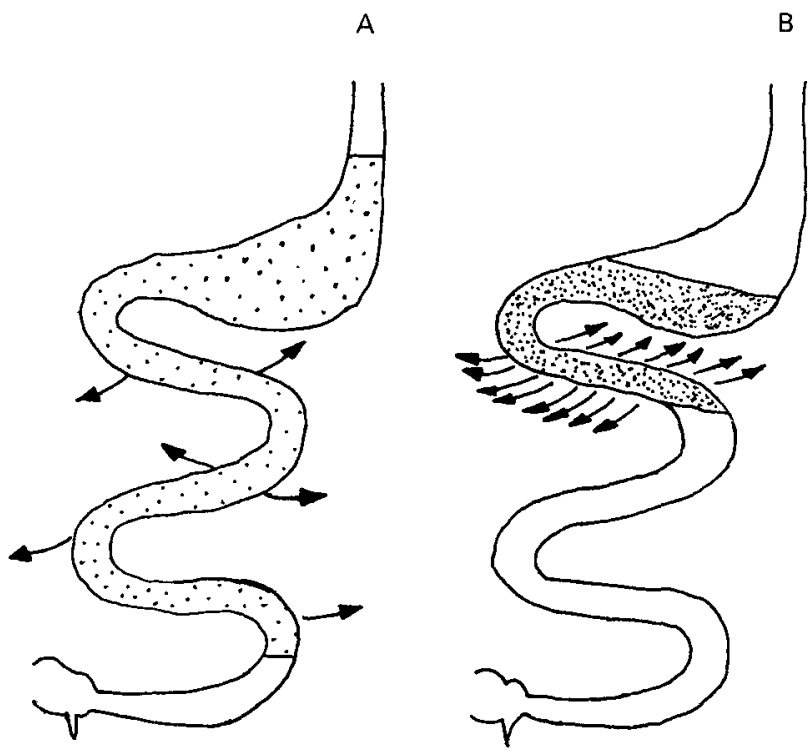

Fig. I. Hypothetical effect on upper gastrointestinal function of feeding high-fibre diets containing low energy density foods (A) and low-fibre diets of high energy density foods (B). $0029-665 \mathrm{I} / 8 \mathrm{I} / 4023-5204 \$ 01.00$ (C) $198 \mathrm{r}$ The Nutrition Society 
A

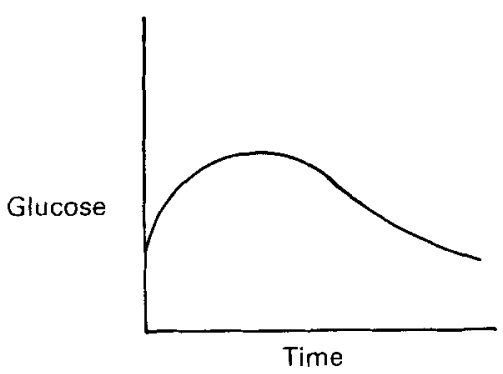

B

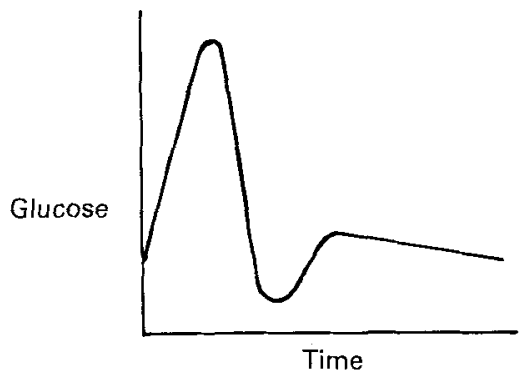

Fig. 2. Hypothetical effect on postprandial blood glucose of feeding high-fibre diets containing low energy density foods (A) and low-fibre diets of high energy density foods (B).

in blood glucose necessitating a greater insulin response. It was reasoned that the latter situation might favour the development of diabetes.

\section{Viscous fibre and slow carbohydrate absorption}

In early studies (Jenkins, D. J. A., Jenkins, M. J. A., Wolever, T. M. S., Taylor, R. H. and Ghafari, H., unpublished observations) a range of fibrous dietary constituents and fibre analogues were added to glucose solution in dialysis bags. All produced some impedance of the outward passage of glucose into the dialysate; the most effective being the most viscous, guar and tragacanth (Fig. 3). The effect of guar in this respect has been confirmed by other workers (Khan et al. 1979).

Addition of a similar range of purified preparations in $12 \mathrm{~g}$ fibre equivalents to $5 \circ \mathrm{g}$ glucose tolerance tests taken by normal volunteers produced a flattening of both the glucose and the insulin responses. Again, guar and tragacanth, the most viscous materials, were the most effective (Jenkins, Wolever, Leeds et al. 1978). The question obviously arose as to whether the flatter glycaemic response was due to slow absorption or whether fibre delayed the absorption of glucose to such an extent as to cause malabsorption. Not only slower absorption in the small intestine but a reduced rate of gastric emptying (Holt et al. 1979) and decreased upper gastrointestinal motility (Thompson et al. 1979) may also be factors. Slower gastric emptying has been shown in isotopic emptying studies after guar and pectin in both normal volunteers (Leeds et al. 1978; Holt et al. 1979) and postgastric surgery patients (Leeds et al. 1978). In addition breath hydrogen studies using lactulose have shown that mouth to caecum transit time is delayed by viscous fibre (Jenkins, Wolever, Leeds et al. 1978). It is of interest that in patients who have had gastric surgery this greatly altered gut motility and blood glucose response has been associated with markedly flattened enteroglucagon and gastric inhibitory peptide responses (Jenkins, Leeds et al. 1980).

In diabetics, addition of guar and pectin to mixed meals has produced even more dramatic flattening in the blood glucose (Jenkins, Leeds et al. 1976; Goulder et al. 1978; Morgan et al. 1979; Levitt et al. 1980), insulin (Jenkins, Leeds et al. 1976; Morgan et al. 1979) and also gastric inhibitory peptide responses (Morgan et al. 1979). This effect was not seen in diabetics with autonomic neuropathy where 


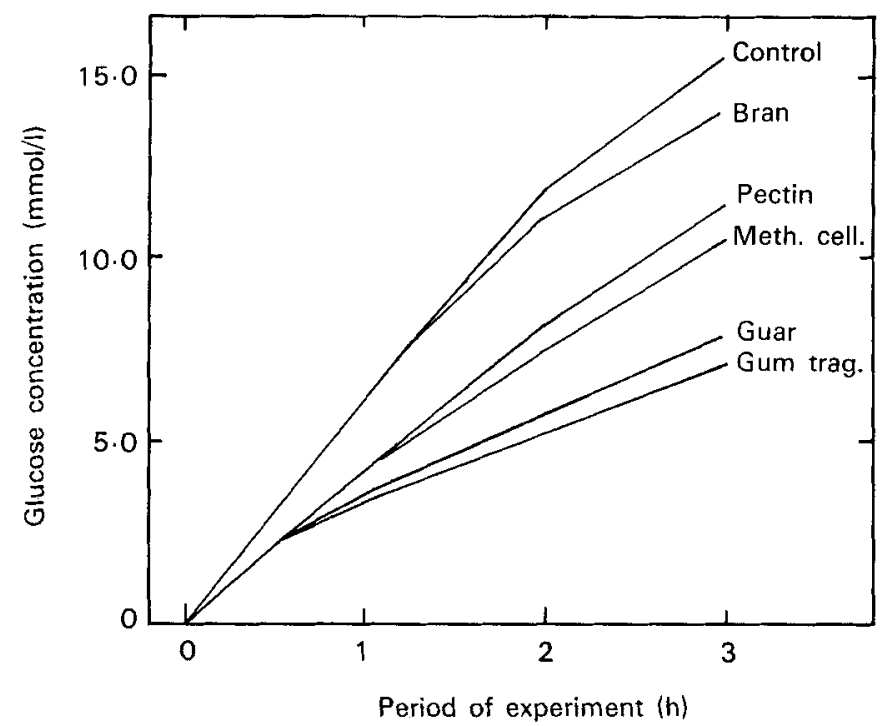

Fig. 3. Effect of adding $\mathrm{I} g$ fibre equivalents of wheat bran, pectin, methyl cellulose, guar gum and gum tragacanth to $30 \mathrm{ml}$ glucose solution containing $3.5 \mathrm{~g}$ glucose. Mixtures were placed in dialysis bags in a water bath and samples of dialysate analyzed for glucose at $\mathrm{x}, 2$ and $3 \mathrm{~h}$.

glucose responses were already greatly flattened and gut secretory, endocrine and motility functions were also depressed (Levitt $e t$ al. $\mathrm{r} 980$ ) as part of the diagnostic criteria for autonomic neuropathy.

\section{Importance of mixing}

Due to the small effect of bran on glucose tolerance (Jeffrys, 1973; Jenkins, Wolever, Leeds et al. 1978; Hall et al. 1980) the effect of fibre on glucose tolerance is often doubted. Nevertheless with viscous fibre, only when it is properly mixed with the carbohydrate portion of the meal is it effective (Williams \& James, 1979; Jenkins, Nineham et al. 1979). This is important since guar taken only 2 min before a glucose tolerance test, is without effect, while when the same amount was mixed with the glucose solution, a marked flattening was seen in the blood glucose response (Jenkins, Nineham et al. 1979).

\section{'Metabolic' effect of fibre}

Guar appears to have the ability to convert glucose into a slowly released carbohydrate which will flatten not only the blood glucose response following a guar glucose mixture but also result in a definite improvement in glucose tolerance when glucose is taken $4 \mathrm{~h}$ later (Jenkins, Wolever, Nineham, Sarson et al. 1980). This improvement can be mimicked if glucose alone is sipped at an even rate over the $4 \mathrm{~h}$ to simulate slow release in the small intestine. Of great interest is the metabolic response where 3 -hydroxybutyrate and FFA were markedly depressed $4 \mathrm{~h}$ after guar and glucose, by comparison with the glucose taken alone, indicating that not only carbohydrate but also fat metabolism may be altered by slow release carbohydrate. 
Viscous fibre and diabetic treatment

In metabolic ward studies twenty-two diabetics, the majority of whom were on insulin, took guar for $5 \mathrm{~d}$ and showed a $50 \%$ reduction in urinary glucose output compared with the $5 \mathrm{~d}$ control period (Jenkins, Wolever, Nineham, Bacon et al. 1979). Interestingly, the reductions were progressive, becoming significant only on the last $2 \mathrm{~d}$ (Jenkins, Wolever, Nineham et al. 1978). In addition, similar reductions were seen in 3-hydroxybutyrate concentrations adding further support to the concept that slow release carbohydrate may be of benefit to the diabetic (Jenkins, Wolever, Nineham, Goff et al. 1979).

Particulate fibre (largely as cellulose) has also been shown to reduce post prandial blood glucose and glucagon responses in diabetic studies under metabolic ward conditions for II d periods (Miranda \& Horwitz, 1978). In addition, wheatbran has been shown to improve glucose tolerance on longer term supplementation of newly diagnosed diabetics who did not require insulin (Bosello et al. I 980 ) as has six month dietary bran supplementation in non-diabetic patients with diverticular disease (Brodribb \& Humphries, 1976). However, the effect of wheat bran on diabetics has not always been confirmed (Cohen et al. I 980 ).

Long-term use of viscous fibre is only possible if palatable supplements are available. A guar crispbread produced by Speywood Laboratories (Bingham, Nottingham) is the only preparation known to the authors where fibre has been effectively premixed with the dietary carbohydrate. Studies on the metabolic ward have shown a halving in urinary glucose output using this product and allowed a $20 \%$ reduction in insulin dose which took place in the first 3 months to be maintained in a group of seven diabetes over a I year period (Jenkins, Wolever, Taylor, Reynolds et al. 1980 ). No falls were seen in serum levels of $\mathrm{Ca}^{++}, \mathrm{PO}_{4}$, $\mathrm{Zn}^{++}$or $\mathrm{Cu}^{++}$. On the other hand, total and LDL cholesterol decreased significantly while HDL cholesterol was unchanged. These findings confirm similar effects of guar crispbread on the serum lipids of hyperlipidaemic patients (Jenkins, Reynolds et al. 1980).

\section{Slow release carbohydrate in whole foods}

In the same way that different fibre preparations may alter the absorption of carbohydrate from the food with which they are mixed so different foods containing the same amount of available carbohydrate also make that carbohydrate available for absorption at different rates. Carbohydrate portions $(2 \mathrm{~g})$ of wholemeal bread, cooked lentils and soya beans mixed with human digestive juices and placed in separate dialysis bags showed a spectrum of rates of release of the carbohydrate they contained which was reminiscent of the effects of adding fibre-glucose mixtures to dialysis bags (Jenkins, Wolever, Taylor, Ghafari et al. I980) (Fig. 4). The wholemeal bread released its carbohydrate products most rapidly and the leguminous seeds much more slowly. Feeding $50 \mathrm{~g}$ carbohydrate portions of those foods to groups of healthy volunteers again demonstrated the importance of the rate of release in determining the blood glucose response. The 


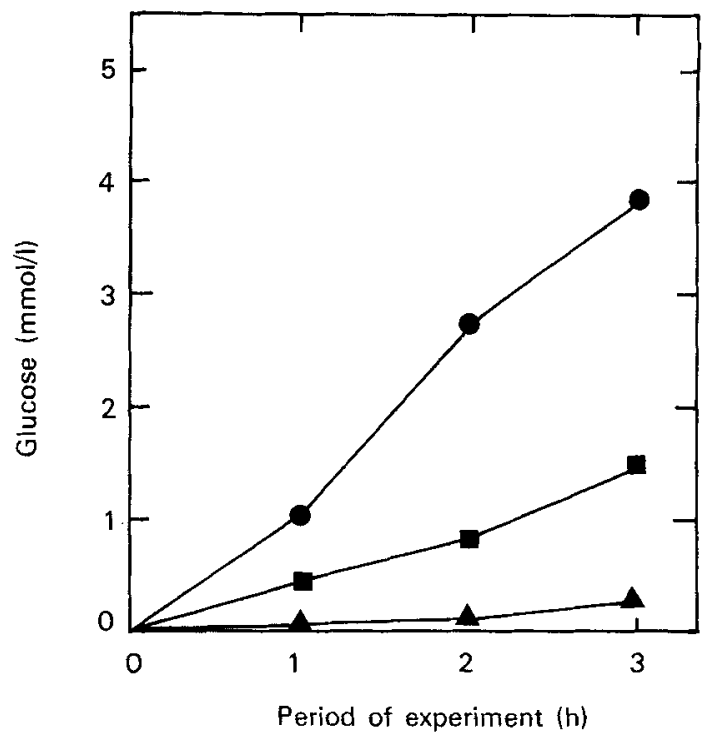

Fig. 4. Concentration of total sugars and oligosaccharides (measured as glucose) in dialysate during in vitro digestion of I $g$ carbohydrate portions of $(\Theta)$ wholemeal bread, $(\square)$ cooked lentils and $(\boldsymbol{\Lambda})$ soya beans (reproduced from Jenkins, Wolever, Taylor, Ghafari et al. Ig80 Br. Med. F.).

wholemeal bread response was well above those of the legumes. Inclusion of results from similar tests on six more leguminous seeds and a range of cereals, cereal products, breads, pasta, breakfast cereals, biscuits and root vegetables showed that as a group, the legumes resulted in a much flatter mean blood glucose curve than the other foods (Jenkins et al. I98I). This difference between legumes and cereals was also demonstrated in a group of diabetics fed breakfast test meals of wholemeal bread and cheese on one occasion and soya beans and lentils on another (Jenkins, Wolever, Taylor, Ghafari et al. 1980) (Fig. 5).

\section{The Glycaemic Index}

Both fibre and food form can modify the glycaemic response to 'available' carbohydrate. This entity, which distinguishes 'available' carbohydrate from the 'unavailable' (dietary fibre), was first derived for a large number of foods by Lawrence \& McCance (1929) in order accurately to determine the carbohydrate contents of Lawrence's diabetic diets. It now seems important that foods should be classified also in respect of their rates of biological availability or the extent to which they raise the blood glucose. We have therefore carried out tests of this nature on over sixty foods and sugars and revealed major differences between foods. For the purpose of comparison the 'Glycaemic index' was calculated as;

area under the $2 \mathrm{~h}$ blood glucose curve after the food

area under the $2 \mathrm{~h}$ blood glucose curve after an equivalent amount of glucose X 100

Where possible, $5 \circ \mathrm{g}$ carbohydrate food portions were taken and the individual 'standardized' with a $5^{\circ} \mathrm{g}$ glucose tolerance test. Thus, with glucose as $100 \%$, 


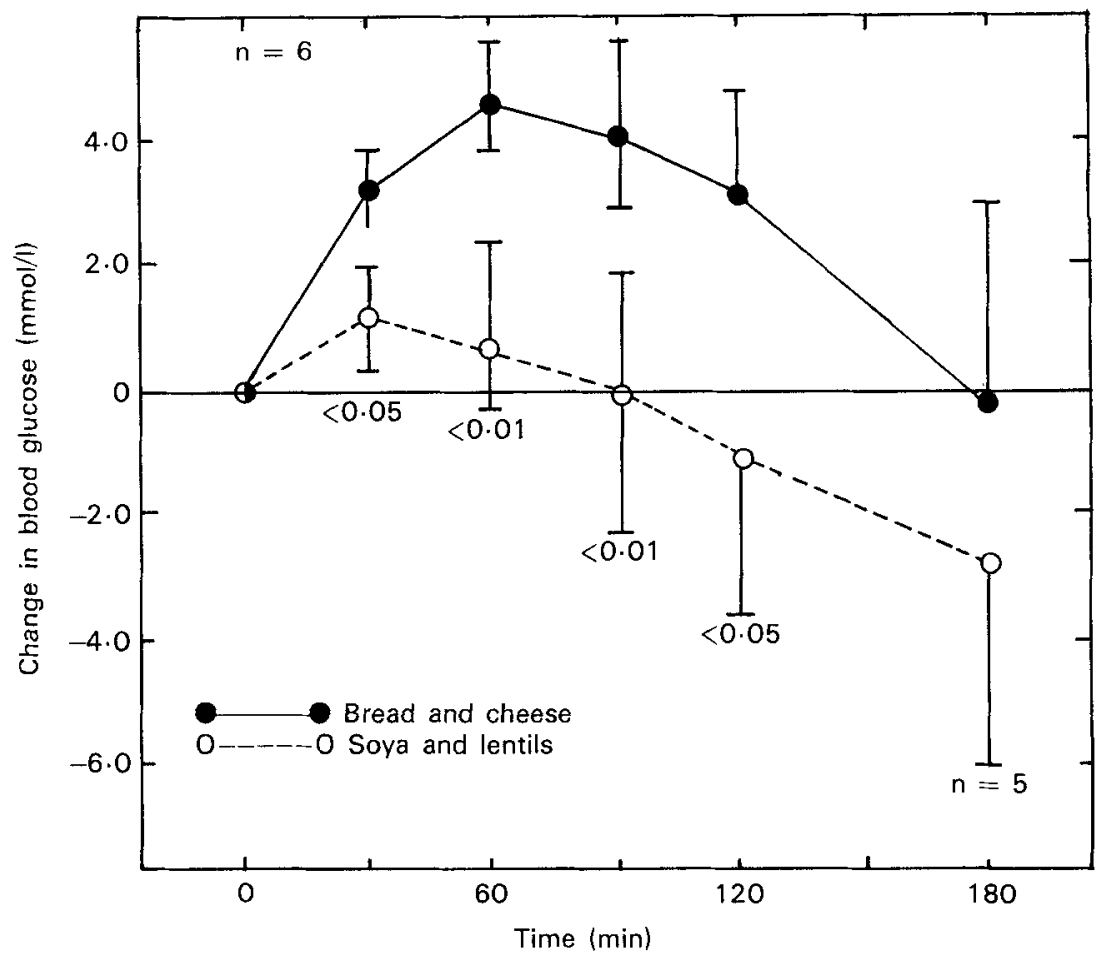

Fig. 5. Rise in blood glucose concentration in six diabetics after meals containing identical amounts of carbohydrate as wholemeal bread or cooked lentils and soya beans (reproduced from Jenkins, Wolever, Taylor, Ghafari et al. 1980, Br. Med. F.).

common foods varied from almost $100 \%$ of their glucose equivalence down to $15 \%$ or less (Jenkins, Wolever, Taylor, Barker et al. I980) (Fig. 6). The fibre content did not seem to be the major factor determining the glycaemic response, stronger negative correlations were seen with fat and protein, while total sugar content, possibly due to galactose and fructose, was unrelated to the blood glucose response. Thus rather than advocating for the diabetic a carbohydrate intake based on chemical analysis it might be more appropriate to try diets composed of low glycaemic index foods. Thereby reducing fat and cholesterol intake and facilitating better diabetic control with slow release carbohydrate.

\section{High-fibre foods and diabetic treatment}

The results of cereal fibre in the diabetic diet have been variable (Bosello et al. I980; Simpson, Mann, Eaton, Carter et al. 1979; Simpson, Mann, Eaton, Moore et al. 1979; Cohen et al. 1980) and where carbohydrate intakes have also been raised, the picture is obscured by the possible effect of high-carbohydrate diets in improving diabetic control (Brunzell et al. 1978; Simpson, Mann, Eaton, Carter et al. I979; Simpson, Mann, Eaton, Moore et al. 1979). There is, however, some evidence for successful use of cereal fibre as bran supplements or wholemeal bread (Bosello et al. 1980; Simpson, Mann, Eaton, Carter et al. 1979; Simpson, Mann, 


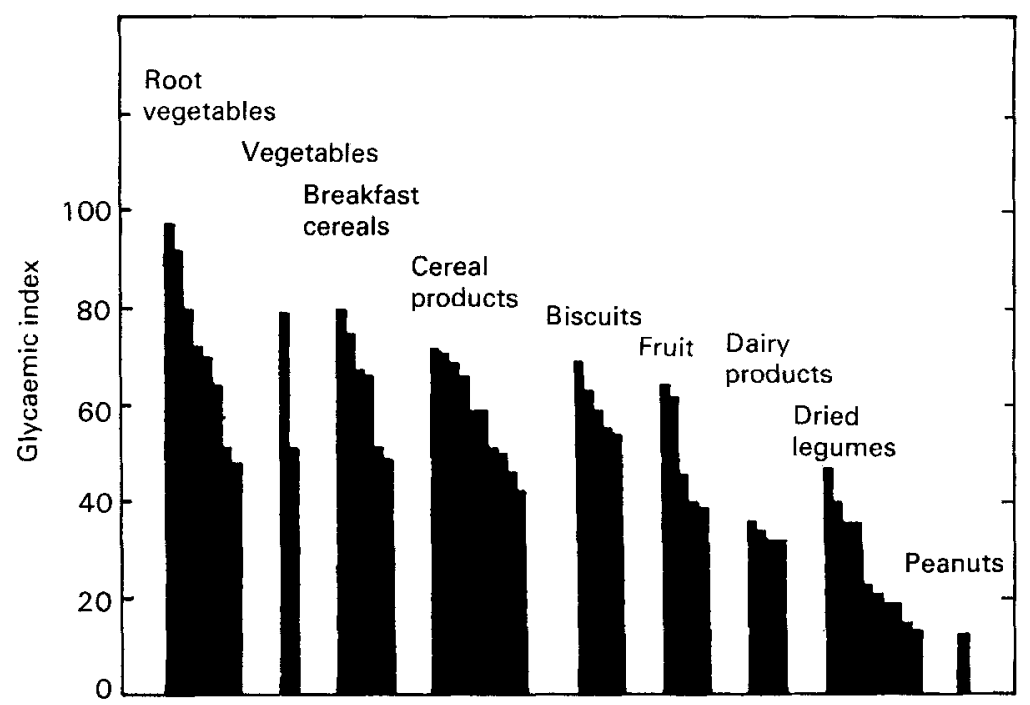

Fig. 6. Glycaemic index of foods (i.e. area under the $2 \mathrm{~h}$ blood glucose response curve of $5 \circ \mathrm{g}$ carbohydrate food portions, $50 \mathrm{~g}$ glucose itself being $100 \%$ ). Each bar in each block represents the mean result for one food tested by $5-10$ individuals.

Eaton, Moore et al. 1979). A possible explanation for this may be that fibre itself is more effective when given with higher carbohydrate intakes (Jenkins, Wolever, Bacon et al. 1980).

The most spectacular results have come from James Anderson and his coworkers (Kiehm et al. 1976; Anderson, 1977; Anderson, 1979) who have been pioneers in this field using diets high in both fibre and carbohydrate taken in as unprocessed cereals, cereal products, leguminous seeds and leafy vegetables. Such high carbohydrate diets might be classed as low glycaemic index diets. Patients who were changed from American Diabetes Association type diets (43\% carbohydrate) to the $70 \%$ carbohydrate high-fibre diets showed improved diabetic control and a greatly reduced insulin requirement. In patients originally on 20 units or less daily, insulin could be withdrawn (Kiehm et al. 1976; Anderson, 1977; Anderson \& Ward 1979) and providing patients kept to 60\% carbohydrate highfibre diets these advantages have been maintained in the outpatient situation. Not only did serum cholesterol fall on these diets but also $50 \%$ reductions in serum triglyceride levels have been reported in both hypertriglyceridaemic diabetics and non-diabetics (Anderson \& Ward 1978; Anderson et al. 1979). This is important at a time when drug therapy, for example with clofibrate, has been shown to have side effects which have limited its use.

\section{Conclusion}

The action of fibre appears to be through slowing the release of glucose in the gastrointestinal tract. Foods also show great differences in the rate at which they release their carbohydrate products of digestion possibly independent of their fibre content. In view of the marked effect of the rate of release in determining the 
glycaemic response and other metabolic events it is suggested that improvements in the diabetic diet may be made by changing some of the emphasis from the quantity to quality of carbohydrate in the diet.

The work was supported by grants to D.J.A.J. from the British Diabetic Association and the Medical Research Council.

\section{REFERENCES}

Anderson, J. W. (1977). Cereal Fds Wld 22, 12.

Anderson, J. W. (1979). Am. F. clin. Nutr. 32, 933.

Anderson, J. W., Midgley, W. R, \& Wedman, B. (1979). Diabetes Care 2, 369.

Anderson, J. W. \& Ward, K. (1978). Diabetes Care 1, 77.

Anderson, J. W. \& Ward, K. (I979). Am. F. clin. Nutr. 32, 23 I2.

Bosello, O., Ostuzzi, R., Armellini, F., Micciolo, R. \& Ludovico, A. S. (I980). Diabetes Care 3 .

Brodribb, A. J. M. \& Humphreys, D. M. (1976). Br. Med. F. 1, 428.

Brunzell, J. D., Learner, R. L \& Hazzard, W. R (1978). New Engl. F. Med. 284, 52 I.

Cohen, M., Leong, V. W., Salmon, E. \& Martin, F. I. R. (1980). Med. F. Aust. 1, 59.

Goulder, T. J., Alberti, K. G. M. M. \& Jenkins, D. J. A. (1978). Diabetes Care I, 35 I.

Hall, S. E. H., Bolton, T. M \& Hetenyi, Jr., G. (I980). Diabetes Care 3, 520.

Holt, S., Heading, R. C., Carter, D. C., Precott, L. F. \& Tothill, P. (1979). Lancet i, 636.

Jeffrys, D. B. (1 973). Proc. Nutr. Soc. 33, i IA.

Jenkins, D. J. A., Leeds, A. R., Bloom, S. R., Sarson, D., Albuquerque, R., Metz, G. L. \& Alberti, K. G. M. M. (1980). (In the Press).

Jenkins, D. J. A., Leeds, A. R., Gassull, M. A., Wolever, T. M. S., Goff, D. V., Alberti, K. G. M. M. \& Hockaday, T. D. R. (1976). Lancet ii, 172 .

Jenkins, D. J. A., Nineham, R. B. A., Craddock, C., Craig-McFeely, P., Donaldson, K., Leigh, T. \& Snook, J. (I979). Lancet i, 434.

Jenkins, D. J. A., Reynolds, D., Slavin, B., Leeds, A. R., Jenkins, A. L. \& Jepson E. M. (Ig80). Am. f. Clin. Nutr. 33, 575 .

Jenkins, D. J. A., Wolever, T. M. S., Bacon, S., Nineham, R., Lees, R., Rowden, R., Love, M. \& Hockaday, T. D R. (1980). Am. F. clin. Nutr. 33 .

Jenkins, D. J. A., Wolever, T. M. S., Leeds, A. R., Gassull, M. A., Haisman, P., Dilawari, J., Goff, D. V., Metz, G. L. \& Alberti, K. G. M. M. (1978). Br. Med. f. I, 1392.

Jenkins, D. J. A., Wolever, T. M. S., Nineham, R., Bacon, S., Smith, R. \& Hockaday, T. D. R. (1979). In Treatment of early diabetes [R. A. Camerini-Davalos, editor]. pp. 275-279. New York: Plenum Press.

Jenkins, D. J. A., Wolever, T. M. S., Nineham, R., Goff, D. V., Haisman, P., Charnock, R., Taylor, R. H., Bacon, S. \& Hockaday, T. D. R. (1979). Br. Med. F. 2, I555.

Jenkins, D. J. A., Wolever, T. M. S., Nineham, R., Sarson, D. L., Bloom, S. R., Ahern, J., Alberti, K. G. M. M. \& Hockaday, T. D. R. (1980). Diabetologia.

Jenkins, D. J. A., Wolever, T. M. S., Nineham, R., Taylor, R., Metz, G. L., Bacon, S. \& Hockaday, T. D. R. (1978). Br. Med. F. 2, I 744 .

Jenkins, D. J. A., Wolever, T. M. S., Taylor, R. H., Barker, H. \& Fielden, H. (1981). Br. Med. $\mathcal{F}$.

Jenkins, D. J. A., Wolever, T. M. S., Taylor, R. H., Barker, H. M., Fielden, H., Baldwin, J. M., Bowling, A. C., Newman, H. C., Jenkins, A. L. \& Goff, D. V. (1980). Am. F. Clin. Nutr.

Jenkins, D. J. A., Wolever, T. M. S., Taylor, R. H., Ghafari, H., Jenkins, A. L. \& Barker, H. (1980). Br. Med. F. 2, I4.

Jenkins, D. J. A., Wolever, T. M. S., Taylor, R. H., Reynolds, D., Nineham, R. \& Hockaday, T. D. R. (1980). Br. Med. 7. I, 1353 .

Khan, P., Macrae, R. \& Robinson, R. K. (1979). Lab Pract. 28, 260.

Kiehm, T. G., Anderson, J. W. \& Ward, K. (1976). Am. F. clin. Nutr. 29, 895.

Lawrence, R. D. \& McCance, R. A. (I929). Br. Med. F. 2, 24 I.

Leeds, A. R., Ralphs, D. N., Boulos, P., Ebied, R., Metz, G. L., Dilawari, J. B., Elliot, A. \& Jenkins, D. J. A. (1978). Proc. Nutr. Soc. 37, 23 A. 
Levitt, S. N., Vinik, A. I., Sive, A. A., Child, P. T. \& Jackson, W. P. U. (1980). Diabetes Care 3, 5I5.

Miranda, P. M. \& Horwitz, D. L. (1978). Ann. Intern. Med. 88, 482.

Morgan, L. M., Goulder, T. J., Tsioladis, D., Marks, V. \& Alberti, K. G. M. M. (1979). Diabetologia $17,85$.

Simpson, R. W., Mann, J. I., Eaton, J., Carter, R. D. \& Hockaday, T. D. R. (I979). Br. Med. J. 2, 523.

Simpson, R. W., Mann, J. I., Eaton, J., Moore, R. A., Carter, R. \& Hockaday, T. D. R. (1979). Br. Med. F. I, 1753 .

Thompson, D. G., Archer, L., Benson, M., Green, W., Hardy, R. \& Wingate, D. L. (I979). Clin. Sci. 57,25 P.

Trowell, H. C. (1975). Diabetes 24, 762 .

Trowell, H. C. \& Burkitt, D. (1975). Artery 3, 107.

Williams, D. R. R. \& James, W. P. T. (1979). Lancet i, 271. 